\title{
Prevalence and Associated Factors of Drug-Related Problems Among Older People: A Cross-Sectional Study at King Chulalongkorn Memorial Hospital in Bangkok
}

\author{
Annie Paisansirikul ${ }^{1}$ D $\cdot$ Armeena Ketprayoon $^{1} \cdot$ Wannee Ittiwattanakul $^{1} \cdot$ Aisawan Petchlorlian $^{2,3}$
}

Accepted: 30 October 2020 / Published online: 12 November 2020

(c) The Author(s) 2020

\begin{abstract}
Background and Objective The use of multiple medications and altered pharmacokinetics/pharmacodynamics may lead to drug-related problems in members of the older population. The aim of this study is to evaluate the prevalence of, and factors related to, drug-related problems in older urban-living Thai people.

Methods We conducted a cross-sectional study involving 466 participants (aged $\geq 65$ years) whose first-time health screening at the Geriatric Excellence Center, King Chulalongkorn Memorial Hospital, Bangkok was between May and October 2019. Participants were interviewed and assessed for drug-related problems by clinical pharmacists.

Results In total, 54.5\% (254) of the participants were aged 65-69 years and 77.0\% (359) of the participants were women. Of the participants, $56.7 \%$ had three or more health conditions such as hyperlipidemia (62\%), hypertension (46\%), and cataract $(18 \%)$. Fifty-five percent of the participants took five or more health products (polypharmacy) and $16 \%$ took ten or more products on a regular basis. Of the 2633 products used, 68\% were prescription drugs and $32 \%$ were over-the-counter products. The prevalence of drug-related problems according to the criteria suggested by Cipolle-Strand-Morley (2012) was 63.3\% (587 drug-related problems). Most of the problems came from: (a) non-adherence (28.6\%); (b) needs for additional drug therapy (26.4\%); and (c) adverse drug reactions (17.4\%). Factors associated with drug-related problems were polypharmacy (odds ratio 2.50, 95\% confidence interval 1.60-3.89) and multiple comorbidities [three or more conditions] (odds ratio 2.20, 95\% confidence interval 1.41-3.43).

Conclusions The prevalence of drug-related problems in urban-living older people at King Chulalongkorn Memorial Hospital in Bangkok was high. Polypharmacy and multiple comorbidities were significantly related to drug-related problems. To decrease the number of drug-related problems, pharmacists should collaborate with healthcare teams and suggest how to correctly reduce the number of health products being consumed by older people.
\end{abstract}

Electronic supplementary material The online version of this article (https://doi.org/10.1007/s40801-020-00219-2) contains supplementary material, which is available to authorized users.

Annie Paisansirikul

anniepaisan@gmail.com

1 Pharmacy Department, King Chulalongkorn Memorial Hospital, The Thai Red Cross Society, 1873 Rama IV Rd, Pathum Wan, Pathum Wan District, Bangkok 10330, Thailand

2 Division of Geriatric Medicine, Department of Medicine, Faculty of Medicine, Chulalongkorn University, 1873 Rama IV Rd, Pathum Wan, Pathum Wan District, Bangkok 10330, Thailand

3 Geriatric Excellence Center, King Chulalongkorn Memorial Hospital, The Thai Red Cross Society, 1873 Rama IV Rd, Pathum Wan, Pathum Wan District, Bangkok 10330, Thailand

\section{Key Points}

Drug-related problems were found in $63 \%$ of urbanliving older people at King Chulalongkorn Memorial Hospital in Bangkok.

Medication non-adherence was the most common problem in older people, followed by needs for additional drug therapy and adverse drug reactions.

Factors significantly linked to drug-related problems were polypharmacy and multiple comorbidities. 


\section{Introduction}

Globally, older people are increasing in number and tend to use multiple medications to treat or prevent their chronic health problems. About 52\% of this study's population used five or more prescribed and over-the-counter products [1]. A decline in several organs' functions, e.g., vision and memory, and changing pharmacokinetics/pharmacodynamics in the normal aging process may lead to a high number of drug-related problems (DRPs) in older people; particularly non-adherence to their medication schedules and adverse drug reactions (ADRs) [2-5]. With older patients, multiple comorbidities and multiple uses of medications place these patients at a high risk of DRPs [6-8]; an issue that can result in morbidity, mortality, and increased healthcare costs [9].

To prevent the adverse events and avoidable costs associated with the older population, identifying DRPs is important in pharmaceutical care practice. There is no consensus on a preference for DRP classification criteria. A DRP is 'any undesirable event experienced by a patient that involves, or is suspected to involve, drug therapy, and that interferes with achieving the desired goals of therapy and which requires professional judgment to resolve', according to the CipolleStrand-Morley (2012) criteria [10]. These classification criteria are widely used for the classification of DRPs in Thailand and other countries [11]. There are seven categories of DRPs: (1) unnecessary drug therapy; (2) needs for additional drug therapy; (3) ineffective drug; (4) dosage too low; (5) ADR, (6) dosage too high; and (7) non-adherence. This classification covers all domains of drug-related needs of patients, including indication, effectiveness, safety, and adherence.

There was a large difference globally in the prevalence of DRPs among older people, ranging from $14.1 \%$ (USA) to $95.9 \%$ (the Netherlands) [6-8, 12-14]. The prevalence of DRPs in Thailand has been studied in the context of the specific disease-related inpatient settings or rural areas; these studies were not focused specifically on older people [15-17]. While the prevalence of DRPs in the general adult population has been documented in Thailand, much less is known about DRPs in older Thai people living in urban areas. The primary objective of this study is to assess the prevalence of DRPs among older urban-living Thai people. The secondary objectives of this study are (1) to evaluate factors associated with DRPs and (2) to evaluate factors associated with categories of DRPs (non-adherence and ADR) in this population.

\section{Methods}

All procedures performed in the present study involving human participants were in accordance with the ethical standards of the institutional and/or national research committee, as well as with the 1964 Helsinki Declaration and its later amendments or comparable ethical standards. The study was approved by the Institutional Review Board of the Faculty of Medicine, Chulalongkorn University, Bangkok, Thailand (No. 120/62). Informed consent was obtained from all individual participants included in the study. The 'Strengthening the Reporting of Observational Studies in Epidemiology (STROBE)' statement was employed to inform the present study at all times [18].

\subsection{Study Design}

A cross-sectional descriptive study.

\subsection{Target Population}

Older urban-living Thai people.

\subsection{Study Population}

Older urban-living Thai people at the Geriatric Excellence Center, the King Chulalongkorn Memorial Hospital (KCMH), Bangkok.

\subsection{Inclusion Criteria}

Participants aged 65 years and older who were in a firsttime health screening program offered by a multidisciplinary team at the outpatient Geriatric Excellence Center, $\mathrm{KCMH}$, Thai Red Cross Society, Bangkok, Thailand between May and October 2019.

\subsection{Exclusion Criteria}

Participants were excluded if they had incomplete medication records or declined to participate in this study.

\subsection{Sample Size}

A consecutive sampling method was employed to recruit participants. A pilot study recruited participants from the Geriatric Excellence Center at the $\mathrm{KCMH}$, Bangkok and found the prevalence of DRPs in the selected population was $63.0 \%$. Using a confidence level of $95 \%$ with a margin of error at $5 \%$, our sample size was 359 . For the multivariate analysis, the sample size was based on the ten events per variable.

\subsection{Study Variables}

The primary outcome of interest in this study was the prevalence of DRPs in an elderly population at the Geriatric Excellence Center, $\mathrm{KCMH}$ in Bangkok. The secondary 
outcomes were prevalence of non-adherence and ADR in this population.

All independent variables were categorical variables:

- Age group: (i) $65-69$ years and (ii) $\geq 70$ years.

- Sex: (i) male and (ii) female.

- Education: (i) lower than a Bachelor's degree and (ii) a Bachelor's degree or higher.

- Occupation: (i) employed and (ii) retired.

- Residence: (i) Bangkok and (ii) outside Bangkok.

- Insurance scheme: (i) capitated scheme (pay a fixed amount per person per year, regardless of treatment costs) and (ii) fee-for-service scheme (reimburse healthcare providers for the cost of each treatment). According to the result, prescription costs for fee-for-service patients are significantly higher than those for capitated patients [19].

- Smoking status: (i) current smoker (100 cigarettes or more in a lifetime and currently smokes cigarettes) and (ii) former smoker $(\geq 100$ cigarettes in a lifetime but had quit smoking at the time of interview) or non-smoker (never smoked, or $<100$ cigarettes in a lifetime).

- Alcohol consumption: (i) regular drinker (alcohol intake three or more times/week) and (ii) occasional drinker (alcohol intake fewer than three times/week) or nondrinker.

- Body mass index: (i) normal weight or underweight $\left(\leq 22.9 \mathrm{~kg} / \mathrm{m}^{2}\right)$ and (ii) overweight or obese $(\geq 23.0 \mathrm{~kg} /$ $\mathrm{m}^{2}$ ), according to classifications for Asian populations [20].

- The risk of cardiovascular events: (i) low-to-moderate risk $(<20 \%)$ and (ii) high risk $(\geq 20 \%)$ predicted by the 10-year Thai cardiovascular risk score [21].

- The risk of falling was defined as a Timed Up and Go Test $\geq 12$ seconds or responding positively to two out of three questions: (1) fallen two or more times in the past year, (2) feel unsteady when walking, or (3) fear of falling.

- The risk of dependency was denoted by registering $<80$ points on the Barthel Activities of Daily Living Index (10-item version). The Barthel Activities of Daily Living Index is used to assess disability; it includes evaluation of independency in feeding, moving from wheelchair to bed and return, grooming, transferring to and from a toilet, bathing, walking on a level surface, going up and down stairs, dressing, and continence of bowels and bladder.

- The risk of cognitive impairment was defined as scoring $<26$ points on the Montreal Cognitive Assessment Test.

- The risk of depression was defined as registering $\geq 5$ points on the Geriatric Depression Scale.

- The risk of malnutrition was defined as scoring $\leq 23.5$ points on the Mini-Nutritional Assessment Test.
- Orthostatic hypotension was defined as a $\geq 20-\mathrm{mmHg}$ drop in systolic blood pressure or $\mathrm{a} \geq 10 \mathrm{mmHg}$ drop in diastolic blood pressure within 3 minutes of rising from lying to standing.

- Sarcopenia was defined as the presence of (1) loss of muscle mass (appendicular skeletal muscle index from bioimpedance analysis $<7.0 \mathrm{~kg} / \mathrm{m}^{2}$ in men and $<5.7$ $\mathrm{kg} / \mathrm{m}^{2}$ in women) and (2) low muscle strength (handgrip strength $<26 \mathrm{~kg}$ for men and $<18 \mathrm{~kg}$ for women) or low physical performance (6-m gait speed $\leq 0.8 \mathrm{~m} / \mathrm{s}$ ), according to the Asian Working Group for Sarcopenia 2014 consensus [22].

- Constipation was defined as frequency of bowel movements fewer than three times/week, straining at defecation, hard feces, or feeling of incomplete evacuation.

- Urinary incontinence was defined as a positive response to one or more out of five questions: (1) urinating more frequently than usual, (2) having a strong urge to void with an inability to make it to the bathroom in time, (3) urine loss with increases in intra-abdominal pressure, such as occurs with laughing, coughing, or sneezing, (4) a slow stream and a sensation of incomplete emptying, or (5) frequent small-volume voids.

- Having sleeping problem was defined as a positive response to one or more out of five questions: (1) using any health product for a sleep problem, (2) difficulty initiating sleep, (3) difficulty maintaining sleep, (4) short sleep duration, or (5) feeling unrestored from sleep.

- A swallowing problem was defined as scoring $\geq 12.5$ points on the Swallowing Disturbance Questionnaire [23].

- Medication management: (i) self-management and (ii) via caregivers.

- History of ADRs was assessed using the Naranjo Probability Scale [24].

- Frequency of health products intake: (i) three or fewer times per day and (ii) more than three times per day, according to the result that consuming a medication four times per day significantly reduced a compliance rate when compared to one to three times per day [25].

- 'Polypharmacy' was defined as regularly taking five or more health products, e.g., prescription drugs, non-prescription drugs, or dietary supplements and 'excessive polypharmacy' was defined as regularly taking ten or more products. These definitions were the most widely used in the literature [26].

- Healthcare facilities for visiting a doctor and receiving prescription drugs: (i) zero or one facility and (ii) two or more facilities.

- Comorbidities reported by doctors according to the International Statistical Classification of Diseases and Related Health, 10th Revision: (i) zero to two conditions and (ii) three or more conditions. 
- Potentially inappropriate medication use was defined as using at least one potentially inappropriate medication according to STOPP (Screening Tool of Older Persons' Prescriptions) 2015 [27] and Beers 2019 criteria [28].

\subsection{Data Collection}

Participants were informed to bring all of their medications and dietary supplements when they visited the Geriatric Excellence Center, KCMH, Bangkok between May and October 2019. The first-time health screening program for older people comprised: (1) assessment of the person's general health status by a nurse and doctor and (2) participant interviews. Procedure (1) involved medical, mental, physical, and environmental factors, e.g., a screening physical examination, as well as checking for: (a) the risk of cardiovascular events; (b) the risk of falling; (c) dependency on activities of daily living; (d) cognitive impairment; (e) depression; (f) malnutrition; and (g) family and social history. In procedure (2), participants were interviewed and assessed by clinical pharmacists regarding their medications and dietary supplements for DRPs, including: (1) medication non-adherence and (2) ADR, according to the CipolleStrand-Morley 2012 criteria [10].

In the interviews, the clinical pharmacists reviewed the participants' medications and dietary supplements and assessed an association between the participants' medical condition and the participants' medication information, to identify DRPs by using instruments mentioned in the next section. The DRPs were recorded using a check list of DRPs with definitions of each category. A medication was grouped according to the Anatomical Therapeutic Chemical classification system. Medication and dietary supplement information such as dosing, frequency, and treatment duration was collected. Participants' characteristics (e.g., medication management, history of ADRs, healthcare facilities for receiving prescription drugs) were also collected. All variables and outcomes were recorded in a case report form. Two clinical pharmacists independently assessed data based on predefined definitions and criteria to minimize bias. Any disagreements between clinical pharmacists were resolved through discussion.

\subsection{Instruments Used to Assess DRP}

\subsubsection{Cipolle-Strand-Morley 2012 Criteria [10]}

These criteria were first defined in 1990 by the research group at the Peters Institute of Pharmaceutical Care at the University of Minnesota. The criteria have been applied to practices in a variety of settings and languages. The newest version is from 2012. A DRP is "any undesirable event experienced by a patient that involves, or is suspected to involve, drug therapy, and that interferes with achieving the desired goals of therapy and which requires professional judgment to resolve". There are seven categories of DRPs. Table 1 presents the descriptions of those seven categories.

Drug-related problems are a consequence of a patient's drug-related needs that have gone unmet. The four drugrelated needs of patients are: (1) indication; (2) effectiveness; (3) safety; and (4) adherence. The first two categories of DRPs are associated with indication. The third and fourth categories of DRPs are associated with effectiveness. The fifth and sixth categories of DRPs are associated with safety. The seventh category deals with patient adherence.

To make a specific description of non-adherence categories, we added a description of non-adherence as an individual taking less than $80 \%$ of the prescribed medications. In the ADR category, the Naranjo Probability Scale [24] was used to assess an ADR when a drug reaction was suspected and the STOPP 2015 [27] and Beers 2019 criteria [28] were used to assess an ADR when participants were taking drug products that were not safe for them.

\subsubsection{STOPP 2015 [27] and Beers 2019 Criteria [28]}

These two explicit criteria were used as adjuncts to assess DRPs in the ADR and unnecessary drug therapy categories. Potentially inappropriate medication stands for a medication whose risks outweigh its benefits, especially when

Table 1 Description of drug-related problem (DRP) categories according to the Cipolle-Strand-Morley 2012 criteria

\begin{tabular}{ll}
\hline Categories of DRPs & Description \\
\hline $\begin{array}{l}\text { 1. Unnecessary drug therapy } \\
\text { 2. Needs for additional drug therapy }\end{array}$ & The drug therapy is unnecessary because the patient does not have a clinical indication at this time \\
3. Ineffective drug & The drug product is not being effective at producing the desired response in the patient \\
4. Dosage too low & The dosage is too low to produce the desired response in the patient \\
$\begin{array}{l}\text { 5. Adverse drug reactions } \\
\text { The drug is causing an adverse reaction that is not dose related in the patient, involving patients } \\
\text { 6. Dosage too high }\end{array}$ & $\begin{array}{l}\text { The dosage is too high, resulting in undesirable effects experienced by the patient } \\
\text { 7. Non-adherence }\end{array}$ \\
\hline
\end{tabular}


more effective alternatives were available [29]. To screen for potentially inappropriate medications, two explicit criteria were employed to cover European and American medications: (1) the STOPP criteria from Europe, with the latest update in 2015 and (2) the American Geriatrics Society Beers criteria, with the latest update in 2019.

\subsubsection{IBM Micromedex ${ }^{\circledR}$ Solutions}

IBM Micromedex ${ }^{\circledR}$ solutions is a source of evidence-based medical information, especially drug information. This resource was used to assess DRPs in aspects of drug indication, drug interactions, drug dosage, and information about ADRs.

\subsubsection{Statistical Analyses}

Descriptive statistics were used to analyze the participants' characteristics and to estimate the prevalence of DRPs in the participants and were expressed as frequency and percentage. A univariate analysis using a chi-square test was conducted to assess associations between outcome (DRP vs non-DRP, adherence vs non-adherence, ADR vs non-ADR) and each independent variable. A $p$-value of less than 0.05 was considered statistically significant. Those factors identified as a $p$ value level of $\leq 0.1$ were subsequently assessed in multivariate analyzes using binary logistic regression. Missing data for all variables were less than 5\%. Subjects with missing data were excluded from the analysis involving the missing variable. All analyses were conducted using the SPSS Statistics for Windows, Version 22.0 (IBM Corp., Armonk, NY, USA).

\section{Results}

Four hundred and seventy-five participants were screened for eligibility: eight participants were excluded because of incomplete medication records and one declined to participate in this study. As a result, 466 participants were included in this study (Fig. 1).

\subsection{Baseline Characteristics}

Among the 466 participants, $54.5 \%$ of the participants were aged $65-69$ years and $77.0 \%$ of the participants were women. Of the participants, $56.7 \%$ had three or more health conditions. More specifically, $61.6 \%$ had hyperlipidemia, $45.9 \%$ had hypertension, and $18.5 \%$ had cataracts. Table 2 shows the demographic data and general health status of the participants. Vaccination and health problems of the participants are shown in the Electronic Supplementary Material (ESM).

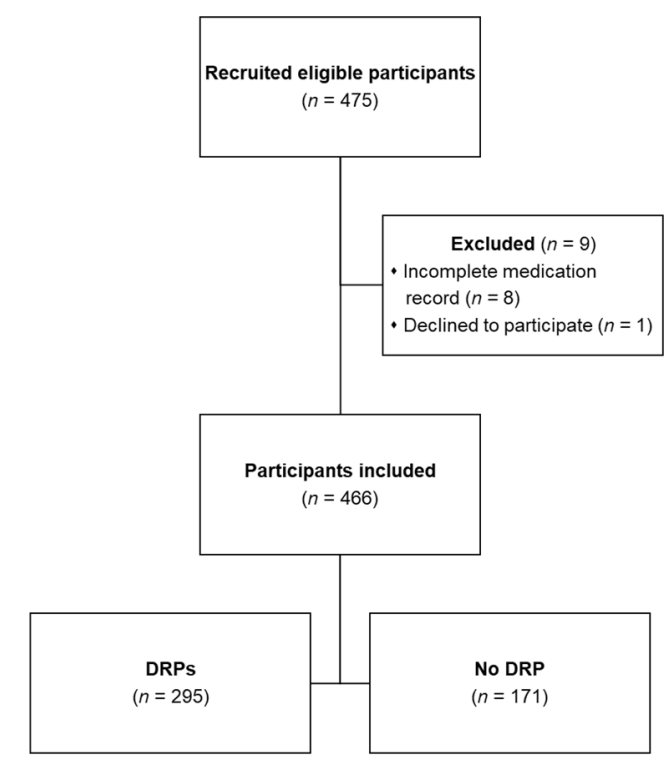

DRPs drug-related problems

Fig. 1 Flow diagram explaining the structure of the cross-sectional study. DRPs drug-related problems

\subsection{Prevalence of DRPs in Older People at the Geriatric Excellence Center, KCMH, Bangkok}

Among the 466 participants, a total number of 587 DRPs (minimum zero, maximum nine) were found in this study. Sixty-three percent $(n=295,63.3 \%)$ of the participants had at least one DRP: $31.5 \%$ had one DRP; $16.5 \%$ had two DRPs, and $15.3 \%$ had three or more DRPs. The prevalence of non-adherence was $24.2 \%(n=113)$; needs for additional drug therapy totaled $25.3 \%(n=118)$, and ADR was $17.4 \%$ $(n=81)$. Categories and causes of DRPs are summarized in Table 3. Based on drug-related needs, DRPs domains in this study were indication (34.6\% of total DRPs), effectiveness (9.0\%), safety (27.8\%), and adherence (28.6\%).

\subsection{Factors Associated with DRPs in Older People at the Geriatric Excellence Center, $\mathrm{KCMH}$, Bangkok}

The univariate analysis for factors associated with DRPs is shown in Table 2. The multivariate analysis for the factors is shown in Table 4.

In the binary logistic regression, two variables retained significance. They were polypharmacy [five or more products] (odds ratio [OR] 2.50, 95\% confidence interval [CI] 1.60-3.89) and multiple comorbidities [three or more conditions] (OR 2.20, 95\% CI 1.41-3.43). 
Table 2 Characteristics of the 466 participants from the Geriatric Excellence Center, King Chulalongkorn Memorial Hospital, Bangkok (May to October, 2019)

\begin{tabular}{|c|c|c|c|c|c|c|c|}
\hline Characteristics & $\begin{array}{l}\text { Total } \\
n=466\end{array}$ & $\begin{array}{l}(\%) \\
(100)\end{array}$ & $\begin{array}{l}\text { With DRP } \\
n=295\end{array}$ & $\begin{array}{l}(\%) \\
(63.3)\end{array}$ & $\begin{array}{l}\text { No DRP } \\
n=171\end{array}$ & $\begin{array}{l}(\%) \\
(36.7)\end{array}$ & $p$ value \\
\hline Age, years & & & & & & & $0.047^{*}$ \\
\hline $65-69$ & 254 & $(54.5)$ & 150 & $(50.8)$ & 104 & $(60.8)$ & \\
\hline$\geq 70$ & 212 & $(45.5)$ & 145 & $(49.2)$ & 67 & $(39.2)$ & \\
\hline Sex & & & & & & & 0.957 \\
\hline Male & 107 & $(23.0)$ & 67 & $(22.7)$ & 40 & (23.4) & \\
\hline Female & 359 & $(77.0)$ & 228 & $(77.3)$ & 131 & $(76.6)$ & \\
\hline Education $(n=465)^{\mathrm{a}}$ & & & & & & & 0.560 \\
\hline Lower than Bachelor's degree & 208 & $(44.7)$ & 128 & $(43.5)$ & 80 & $(46.8)$ & \\
\hline Bachelor's degree or higher & 257 & $(55.3)$ & 166 & $(56.5)$ & 91 & $(53.2)$ & \\
\hline Occupation $(n=463)^{\mathrm{a}}$ & & & & & & & 0.720 \\
\hline Employed & 81 & $(17.5)$ & 53 & $(18.2)$ & 28 & $(16.4)$ & \\
\hline Retired & 382 & $(82.5)$ & 239 & $(81.8)$ & 143 & $(83.6)$ & \\
\hline Residence & & & & & & & 1.000 \\
\hline Bangkok & 405 & $(86.9)$ & 256 & $(86.8)$ & 149 & $(87.1)$ & \\
\hline Outside Bangkok & 61 & $(13.1)$ & 39 & $(13.2)$ & 22 & $(12.9)$ & \\
\hline Insurance scheme $(n=463)^{a}$ & & & & & & & 0.171 \\
\hline Capitated & 331 & $(71.5)$ & 204 & $(69.2)$ & 127 & $(75.6)$ & \\
\hline Fee-for-service & 132 & $(28.5)$ & 91 & $(30.8)$ & 41 & $(24.4)$ & \\
\hline Smoking status & & & & & & & 1.000 \\
\hline Current smoker & 3 & $(0.6)$ & 2 & $(0.7)$ & 1 & $(0.6)$ & \\
\hline Former smoker or non-smoker & 463 & $(99.4)$ & 293 & $(99.3)$ & 170 & $(99.4)$ & \\
\hline Alcohol consumption & & & & & & & 0.521 \\
\hline Regular drinker & 42 & $(9.0)$ & 29 & $(9.8)$ & 13 & (7.6) & \\
\hline Occasional drinker or non-drinker & 424 & $(91.0)$ & 266 & $(90.2)$ & 158 & $(92.4)$ & \\
\hline Body mass index & & & & & & & 0.486 \\
\hline Normal weight or underweight $\left(\leq 22.9 \mathrm{~kg} / \mathrm{m}^{2}\right)$ & 196 & $(42.1)$ & 120 & $(40.7)$ & 76 & $(44.4)$ & \\
\hline Overweight $\left(23.0-24.9 \mathrm{~kg} / \mathrm{m}^{2}\right)$ & 118 & $(25.3)$ & 75 & $(25.4)$ & 43 & $(25.1)$ & \\
\hline Obese $\left(\geq 25.0 \mathrm{~kg} / \mathrm{m}^{2}\right)$ & 152 & $(32.6)$ & 100 & $(33.9)$ & 52 & $(30.4)$ & \\
\hline Risk of cardiovascular events $(n=464)^{a}$ & & & & & & & $0.010^{*}$ \\
\hline Low-to-moderate risk $(<20 \%)$ & 288 & $(62.1)$ & 169 & $(57.5)$ & 119 & $(70.0)$ & \\
\hline High risk $(\geq 20 \%)$ & 176 & $(37.9)$ & 125 & $(42.5)$ & 51 & $(30.0)$ & \\
\hline Risk of falling $(n=464)^{\mathrm{a}}$ & & & & & & & 0.136 \\
\hline Yes & 53 & $(11.4)$ & 39 & $(13.3)$ & 14 & $(8.2)$ & \\
\hline No & 411 & $(88.6)$ & 255 & $(86.7)$ & 156 & $(91.8)$ & \\
\hline Risk of dependency [Barthel ADL index $<80$ points] $(n=465)^{a}$ & 0 & $(0.0)$ & 0 & $(0.0)$ & 0 & $(0.0)$ & - \\
\hline Risk of cognitive impairment $\left[\mathrm{MoCA}<26\right.$ points] $(\mathrm{n}=460)^{\mathrm{a}}$ & & & & & & & 0.384 \\
\hline Yes & 133 & $(28.9)$ & 89 & $(30.5)$ & 44 & $(26.2)$ & \\
\hline No & 327 & $(71.1)$ & 203 & $(69.5)$ & 124 & $(73.8)$ & \\
\hline Risk of depression [GDS $\geq 5$ points] $(n=465)^{a}$ & & & & & & & 1.000 \\
\hline Yes & 15 & $(3.2)$ & 9 & $(3.1)$ & 6 & $(3.5)$ & \\
\hline No & 450 & $(96.8)$ & 285 & $(96.9)$ & 165 & $(96.5)$ & \\
\hline Risk of malnutrition $\left[\mathrm{MNA} \leq 23.5\right.$ points] $(\mathrm{n}=444)^{\mathrm{a}}$ & & & & & & & 1.000 \\
\hline Yes & 16 & $(3.6)$ & 10 & $(3.6)$ & 6 & $(3.7)$ & \\
\hline No & 428 & $(96.4)$ & 270 & $(96.4)$ & 158 & $(96.3)$ & \\
\hline Orthostatic hypotension & & & & & & & 0.650 \\
\hline Yes & 29 & $(6.2)$ & 20 & $(6.8)$ & 9 & $(5.3)$ & \\
\hline No & 437 & $(93.8)$ & 275 & $(93.2)$ & 162 & $(94.7)$ & \\
\hline Sarcopenia $(n=463)^{a}$ & & & & & & & 0.899 \\
\hline
\end{tabular}


Table 2 (continued)

\begin{tabular}{|c|c|c|c|c|c|c|c|}
\hline Characteristics & $\begin{array}{l}\text { Total } \\
n=466\end{array}$ & $\begin{array}{l}(\%) \\
(100)\end{array}$ & $\begin{array}{l}\text { With DRP } \\
n=295\end{array}$ & $\begin{array}{l}(\%) \\
(63.3)\end{array}$ & $\begin{array}{l}\text { No DRP } \\
n=171\end{array}$ & $\begin{array}{l}(\%) \\
(36.7)\end{array}$ & $p$ value \\
\hline Yes & 68 & $(14.7)$ & 44 & $(15.0)$ & 24 & $(14.1)$ & \\
\hline No & 395 & $(85.3)$ & 249 & $(85.0)$ & 146 & $(85.9)$ & \\
\hline Constipation & & & & & & & 0.163 \\
\hline Yes & 55 & $(11.8)$ & 40 & $(13.6)$ & 15 & $(8.8)$ & \\
\hline No & 411 & $(88.2)$ & 255 & $(86.4)$ & 156 & $(91.2)$ & \\
\hline Urinary incontinence & & & & & & & 0.086 \\
\hline Yes & 172 & $(36.9)$ & 118 & $(40.0)$ & 54 & $(31.6)$ & \\
\hline No & 294 & $(63.1)$ & 177 & $(60.0)$ & 117 & $(68.4)$ & \\
\hline Sleeping problem $(n=465)^{a}$ & & & & & & & 0.082 \\
\hline Yes & 115 & $(24.7)$ & 81 & $(27.6)$ & 34 & $(19.9)$ & \\
\hline No & 350 & $(75.3)$ & 213 & $(72.4)$ & 137 & $(80.1)$ & \\
\hline Swallowing problem & 0 & $(0.0)$ & 0 & $(0.0)$ & 0 & $(0.0)$ & - \\
\hline Medication management & & & & & & & 1.000 \\
\hline Caregiver & 10 & $(2.1)$ & 6 & $(2.0)$ & 4 & $(2.3)$ & \\
\hline Self-management & 456 & $(97.9)$ & 289 & $(98.0)$ & 167 & $(97.7)$ & \\
\hline History of adverse drug reactions & & & & & & & 0.266 \\
\hline Yes & 158 & $(33.9)$ & 106 & $(35.9)$ & 52 & $(30.4)$ & \\
\hline No & 308 & $(66.1)$ & 189 & $(64.1)$ & 119 & $(69.6)$ & \\
\hline Frequency of health products intake, times per day & & & & & & & $0.015^{*}$ \\
\hline$\leq 3$ & 416 & $(89.3)$ & 255 & $(86.4)$ & 161 & $(94.2)$ & \\
\hline$>3$ & 50 & $(10.7)$ & 40 & $(13.6)$ & 10 & $(5.8)$ & \\
\hline Polypharmacy ( $\geq 5$ products) & & & & & & & $<0.001^{*}$ \\
\hline Yes & 257 & $(55.2)$ & 195 & $(66.1)$ & 62 & $(36.3)$ & \\
\hline No & 209 & $(44.8)$ & 100 & $(33.9)$ & 109 & $(63.7)$ & \\
\hline Healthcare facilities for receiving prescription drugs & & & & & & & $0.001^{*}$ \\
\hline $0-1$ facility & 359 & $(77.0)$ & 212 & $(71.9)$ & 147 & $(86.0)$ & \\
\hline$\geq 2$ facilities & 107 & $(23.0)$ & 83 & (28.1) & 24 & $(14.0)$ & \\
\hline Comorbidities & & & & & & & $<0.001^{*}$ \\
\hline $0-2$ conditions & 202 & $(43.3)$ & 96 & $(32.5)$ & 106 & $(62.0)$ & \\
\hline$\geq 3$ conditions & 264 & $(56.7)$ & 199 & $(67.5)$ & 65 & $(38.0)$ & \\
\hline
\end{tabular}

Barthel ADL index Barthel Activities of Daily Living Index, DRPs drug-related problems, GDS Geriatric Depression Scale, MNA Mini-Nutritional Assessment Test, MoCA Montreal Cognitive Assessment Test

${ }^{*} p<0.05$ was considered statistical significance

${ }^{a}$ Missing data

\subsection{Factors Related to Categories of DRPs in Older People at the Geriatric Excellence Center, KCMH, Bangkok}

From the seven categories of DRPs, non-adherence and ADR were the two major categories of DRPs identified in this study.

\subsubsection{Factors Related to the Non-adherence Category}

The univariate analysis for factors related to the non-adherence category is given in the ESM. The multivariate analysis for the factors is shown in Table 5 .
Three variables retained significance in the binary logistic regression. They were: (1) risk of cardiovascular events [high risk $\geq 20 \%$ ] (OR 1.60, 95\% CI 1.02-2.50); (2) polypharmacy [five or more products] (OR $1.89,95 \%$ CI 1.16-3.10); and (3) multiple healthcare facilities [two or more facilities] (OR 2.18, 95\% CI 1.33-3.60).

\subsubsection{Factors Related to ADR Category}

The univariate analysis for factors related to the ADR category is given in the ESM. The multivariate analysis for the factors is shown in Table 6. 
Table 3 Categories and causes of drug-related problems (DRPs) identified in older people at the Geriatric Excellence Center, King Chulalongkorn Memorial Hospital, Bangkok ( $n=587$ DRPs)

\begin{tabular}{|c|c|c|c|}
\hline Category & $\begin{array}{l}\text { Total } \\
n=587\end{array}$ & $(\%)(100)$ & Drugs most frequently involved in each category (no. of DRPs) \\
\hline Non-adherence (domain: adherence) & 168 & $(28.6)$ & $\begin{array}{l}\text { Simvastatin (21), calcium (15), amlodipine (11), vitamin D } \\
\text { (11) }\end{array}$ \\
\hline Patient prefers not to take & 82 & $(48.8)$ & \\
\hline Patient forgets to take & 47 & $(28.0)$ & \\
\hline Does not understand instructions & 34 & $(20.2)$ & \\
\hline Cannot afford drug product & 3 & $(1.8)$ & \\
\hline Drug product not available & 1 & $(0.6)$ & \\
\hline Cannot administer drug & 1 & $(0.6)$ & \\
\hline Needs for additional drug therapy (domain: indication) & 155 & $(26.4)$ & Statins (66), vitamin D (17), calcium (9) \\
\hline Untreated condition & 131 & $(84.5)$ & \\
\hline Synergistic therapy & 17 & $(11.0)$ & \\
\hline Preventive therapy & 7 & $(4.5)$ & \\
\hline Adverse drug reactions (domain: safety) & 102 & $(\mathbf{1 7 . 4})$ & Lorazepam (17), clonazepam (9), orphenadrine (6) \\
\hline Unsafe drug for the patient & 87 & $(85.3)$ & \\
\hline Undesirable effect & 9 & $(8.8)$ & \\
\hline Drug interaction & 6 & $(5.9)$ & \\
\hline Dosage too high (domain: safety) & 61 & $(\mathbf{1 0 . 4})$ & $\begin{array}{l}\text { Omeprazole (7), simvastatin (7), enalapril (5), senna (5), } \\
\text { amlodipine (4) }\end{array}$ \\
\hline Dose too high & 20 & $(32.8)$ & \\
\hline Duration too long & 20 & $(32.8)$ & \\
\hline Needs additional monitoring & 16 & $(26.2)$ & \\
\hline Frequency too short & 5 & $(8.2)$ & \\
\hline Unnecessary drug therapy (domain: indication) & 48 & (8.2) & $\begin{array}{l}\text { Calcium with vitamin } D(4) \text {, vitamin } B_{1}, B_{6} \text {, and } B_{12}(4) \text {, } \\
\text { aspirin (3), metformin (3), multivitamins and miner- } \\
\text { als (3), artificial tear (2), calcium (2), doxazosin (2) }\end{array}$ \\
\hline Duplicate therapy & 31 & $(64.6)$ & \\
\hline Nondrug therapy more appropriate & 10 & $(20.8)$ & \\
\hline No medical indication at this time & 6 & $(12.5)$ & \\
\hline Treating avoidable adverse reaction & 1 & $(2.1)$ & \\
\hline Dosage too low (domain: effectiveness) & 44 & (7.5) & Simvastatin (7), losartan (6), enalapril (3) \\
\hline Ineffective dose & 39 & $(88.6)$ & \\
\hline Drug interaction & 3 & $(6.8)$ & \\
\hline Frequency inappropriate & 2 & $(4.5)$ & \\
\hline Ineffective drug (domain: effectiveness) & 9 & (1.5) & $\begin{array}{l}\text { Simvastatin (3), artificial tear (1), bisoprolol (1), cetirizine } \\
\text { (1), colchicine (1), insulin (1), vitamin D (1) }\end{array}$ \\
\hline More effective drug available & 8 & $(88.9)$ & \\
\hline Contraindication present & 1 & $(11.1)$ & \\
\hline
\end{tabular}

Four variables retained significance in the binary logistic regression. They were: (1) risk of falling (OR 2.05, 95\% CI 1.01-4.16); (2) sleeping problem (OR 2.05, 95\% CI 1.17-3.60); (3) frequent product intake [more than three times per day] (OR 2.56, 95\% CI 1.32-4.95); and (4) polypharmacy [five or more products] (OR $10.67,95 \%$ CI 4.46-25.55).

\subsection{Polypharmacy and Dietary Supplement Use}

In total, $55.2 \%$ of the 466 participants regularly took five or more health products (polypharmacy), 39.3\% took five to nine products, and $15.9 \%$ took ten or more products (excessive polypharmacy). Twenty-three percent of the participants received prescription drugs from multiple healthcare facilities (two or more facilities). 
Table 4 Multivariate analysis for factors associated with drug-related problems in the 466 older people at the Geriatric Excellence Center, King Chulalongkorn Memorial Hospital, Bangkok (May to October, 2019)

\begin{tabular}{lll}
\hline Factors & Adjusted $\mathrm{OR}^{\mathrm{a}}$ & $95 \% \mathrm{CI}$ \\
\hline $\begin{array}{l}\text { Polypharmacy ( } \geq 5 \text { prod- } \\
\text { ucts) }\end{array}$ & 2.50 & $1.60-3.89$ \\
$\begin{array}{l}\text { Multiple comorbidities } \\
(\geq 3 \text { conditions) }\end{array}$ & 2.20 & $1.41-3.43$ \\
\hline
\end{tabular}

$C I$ confidence interval, $O R$ odds ratio

a Adjusted factors: age, risk of cardiovascular events, urinary incontinence, sleeping problem, frequency of health products intake, and healthcare facilities for receiving prescription drugs

Table 5 Multivariate analysis for factors associated with non-adherence in the 466 older people at the Geriatric Excellence Center, King Chulalongkorn Memorial Hospital, Bangkok (May to October 2019)

\begin{tabular}{lll}
\hline Factors & Adjusted OR & $95 \%$ CI \\
\hline $\begin{array}{l}\text { Risk of cardiovascular events }(n= \\
\quad 164)^{\mathrm{b}} \text { [high risk } \geq 20 \% \text { ] }\end{array}$ & 1.60 & $1.02-2.50$ \\
$\begin{array}{l}\text { Polypharmacy }(\geq 5 \text { products) } \\
\text { Healthcare facilities for receiving } \\
\text { prescription drugs }(\geq 2 \text { facilities) }\end{array}$ & 2.18 & $1.16-3.10$ \\
\hline
\end{tabular}

$C I$ confidence interval, $O R$ odds ratio

adjusted factors: age, risk of cognitive impairment, sleeping problem, frequency of health products intake, potentially inappropriate medications used, and comorbidities

${ }^{\mathrm{b}}$ Missing data

Table 6 Multivariate analysis for factors associated with adverse drug reactions in the 466 older people at the Geriatric Excellence Center, King Chulalongkorn Memorial Hospital, Bangkok (May to October 2019)

\begin{tabular}{lll}
\hline Factors & Adjusted $\mathrm{OR}^{\mathrm{a}}$ & $95 \% \mathrm{CI}$ \\
\hline Risk of falling $(n=464)^{\mathrm{b}}$ & 2.05 & $1.01-4.16$ \\
Sleeping problem $(n=465)^{\mathrm{b}}$ & 2.05 & $1.17-3.60$ \\
Frequency of health products & 2.56 & $1.32-4.95$ \\
$\quad$ intake $(>3$ times per day) & & \\
Polypharmacy $(\geq 5$ products $)$ & 10.67 & $4.46-25.55$ \\
\hline
\end{tabular}

$C I$ confidence interval, $O R$ odds ratio

${ }^{a}$ Adjusted factors: urinary incontinence, medication management, history of adverse drug reactions, healthcare facilities for receiving prescription drugs, and comorbidities

${ }^{\mathrm{b}}$ Missing data

A total of 2633 health products were regularly used, with a maximum of 24 products per participant. Sixty-eight percent $(68.1 \%)$ of the products were prescription drugs, $28.8 \%$ were dietary supplements, and $3.1 \%$ were non-prescription drugs. The most frequently used classes of prescription drugs were: (a) cardiovascular agents $(63.3 \%$ of participants), followed by (b) alimentary tract and metabolism agents $(48.3 \%)$, (c) ophthalmological agents $(25.1 \%)$, (d) blood-forming agents (23.4\%), (e) musculoskeletal agents $(18.9 \%)$, and (f) nervous system agents (16.5\%). The most commonly used prescription drugs were simvastatin (25.8\% of participants), lubricating eye drops [artificial tear] (21.9\%), calcium (21.5\%), vitamin D (20.4\%), and amlodipine $(17.0 \%)$. The top ten prescription drugs used by the participants are given in the ESM.

Thirty-seven percent (37.1\%) of the participants regularly used at least one dietary supplement. Vitamins were the most frequently used (31.1\% of participants), followed by herbs and botanicals (30.7\%), specialty class, e.g., fish oil, glucosamine, collagen (29.0\%), multivitamins and minerals (17.8\%), and minerals (7.9\%). The most commonly used dietary supplements were vitamin C (17.6\% of participants), fish oil (12.4\%), multivitamins and minerals (10.3\%), vitamin $\mathrm{B}_{1}, \mathrm{~B}_{6}$, and $\mathrm{B}_{12}(9.9 \%)$, and calcium with vitamin $\mathrm{D}$ $(9.2 \%)$. The top ten dietary supplements used by the participants are presented in the ESM.

Interactions between medications and dietary supplements were found, i.e., non-steroidal anti-inflammatory drug-Ginkgo biloba and antiplatelet agent curcumin, which may increase the risk of bleeding. Interactions, i.e., antidiabetic agent glucosamine, omeprazole-Ginkgo biloba, and levothyroxine-calcium, may decrease a drug's effectiveness.

\section{Discussion}

The prevalence of DRPs in 466 older people at the Geriatric Excellence Center, KCMH, Bangkok was high (63.3\%). Factors significantly associated with DRPs among participants were polypharmacy and multiple comorbidities. In this study, participants with polypharmacy presented a risk of having at least one DRP 2.50 times greater than participants in a non-polypharmacy category. In addition, participants with multiple comorbidities presented a risk of having at least one DRP 2.20 times greater than participants with nonmultiple comorbidities.

To the best of our knowledge, this is the first study of prevalence and associated factors of DRPs in older Thai people living in urban areas. This study used the CipolleStrand-Morley (2012) classification, the newest version [10], to report DRPs. The prevalence of DRPs in older people across the world ranged from 14.1 to $95.9 \%$ [6-8, 12-14]. In an outpatient setting, there were three studies of DRPs in older people and their prevalence of DRPs ranged from 60.4 to $95.2 \%[6,12,13]$. The wide range may be influenced by the use of: (a) different criteria and test versions to identify DRPs, such as Pharmaceutical Care Network Europe (PCNE) [9]; (b) the different study settings and locations, 
which had different participant characteristics; and (c) different medication prescribing patterns, which made comparing studies difficult.

In this study, the prevalence of DRPs in older people at $\mathrm{KCMH}$, Bangkok was high (63.3\%) and consistent with the study in Brazil (60.4\%) [12], but it was roughly $24 \%$ and 32\% lower than the studies in Taiwan (87.0\%) [6], and Michigan (95.2\%) [13]. Participants in the two latter studies had a higher number of medications and comorbidities than participants in the present study. Previous studies have indicated these factors increased the number of DRPs [6-8, 30]. In this study, polypharmacy and multiple comorbidities were related to DRPs, consistent with previous research.

From the seven categories of DRPs, the medication nonadherence category was the most common problem in this study, followed by needs for additional drug therapy and ADR categories. Medication-non adherence was found to be associated with all causes of hospitalization and mortality in older people [31]. Using different criteria to identify non-adherence and differences in study populations limited the possibility of comparing the research results with other studies. The prevalence of medication non-adherence in this study was $24.2 \%$ and consistent with the study in Brazil (21.5\%) [12], compared with the study in Taiwan (40\%) [6]. The Taiwan participants had a larger number of medications than the Thai participants. Polypharmacy had contradictory results on medication adherence in older people in the literature; however, most of the studies suggested that polypharmacy negatively affected medication adherence $[32,33]$. Factors significantly associated with non-adherence found in this study were polypharmacy, high risk of cardiovascular events, and multiple healthcare facilities.

The ADR category was an important health issue, with $10 \%$ of all elderly patients admitted to hospital experiencing an ADR leading to their hospital admission. [5]. Prevalence of the ADR category in the present study was $17.4 \%$, different from the study in Pakistan (10.7\%) [34]. The prevalence varied with different study designs and how ADR was defined. Participants who were taking drug products that are not safe for them and who were involved in the present study might have caused a higher prevalence of ADR. Factors significantly associated with ADR category in this study were having a risk of falling, having sleeping problems, frequent product intake, and polypharmacy. Consistent with the findings from other studies was that polypharmacy is a factor associated with ADR in older people; both in outpatient [34] and inpatient settings [5]. Whereas, a patient's history of falls was a factor associated with ADR in a study of older people in an inpatient setting [5].

More than half of the older population in this study regularly used five or more health products, including prescription drugs and over-the-counter products. Examples of the latter category were dietary supplements and non-prescription drugs. In the older population, 29-53\% reported using multiple medications. Countries' polypharmacy rates varied [35]; the prevalence of polypharmacy in this study was high (55.2\%) and consistent with a previous study in Malaysia (51.5\%) [1].

Polypharmacy and multiple comorbidities were the factors significantly associated with DRPs among participants in this study. To reduce DRPs in the participants, a future study should, as a priority, explore a proposed solution to decrease the number of health products being prescribed to, or consumed by, older patients.

The limitations of this current study were that first, the sampling was carried out consecutively and may not reflect the population; additionally, the great majority of the participants in this study lived in Bangkok, the capital of Thailand, a trend that might affect the generalizability of these findings. Second, the over-the-counter product data may be deformed by a social desirability bias. For example, the participants may not report certain behavior or habits, such as the use of cannabis. This possibility, if present, may cause an underestimation of the number of products used and the level of DRPs in the older people. Third, the participants who were not given pneumococcal or influenza vaccinations as routine were not categorized in the 'in need of additional drug therapy' category; thus, the number of DRPs identified might have been underestimated. It should be noted that during the study period, geriatric pneumococcal vaccinations were not provided by the national healthcare coverage in Thailand, and geriatric influenza vaccinations were only distributed cost free during particular seasons and in limited quantities. These factors may impact participants' decisions to vaccinate or not to vaccinate. To minimize the limitation, a future study should use probability sampling to be more representative of the target population.

\section{Conclusions}

The prevalence of DRPs among older people at the Geriatric Excellence Center, $\mathrm{KCMH}$ in Bangkok, Thailand was high (63.3\%). The top three DRPs were: (1) non-adherence, (2) needs for additional therapy, and (3) ADRs. Factors significantly associated with DRPs were polypharmacy and multiple comorbidities. Future research focused on minimizing these factors, especially polypharmacy among older urbanliving Thai people, is needed to reduce the level of DRPs in the older population.

Acknowledgements The authors thank the multidisciplinary team and participants at the Geriatric Excellence Center, King Chulalongkorn Memorial Hospital, Thailand for their cooperation, Associate Prof. Mayuree Tangkiatkumjai, Faculty of Pharmacy, Srinakharinwirot University, Thailand for research consulting, and Wasan Punyasang, 
Research Affairs, Faculty of Medicine, Chulalongkorn University, Thailand for statistical consulting.

\section{Declarations}

Funding No funding was received for the conduct of this study or the preparation of this article.

Conflict of interest Annie Paisansirikul, Armeena Ketprayoon, Wannee Ittiwattanakul, and Aisawan Petchlorlian have no conflicts of interest that are directly relevant to the content of this article.

Ethics approval All procedures performed in the current study involving human participants were in accordance with the ethical standards of the institutional and/or national research committee and with the 1964 Helsinki Declaration and its later amendments or comparable ethical standards. The study was approved by the Institutional Review Board of the Faculty of Medicine, Chulalongkorn University, Bangkok, Thailand (No. 120/62).

Consent to participate Informed consent was obtained from all participants included in the study.

Availability of Data and Material The datasets generated during and/or analyzed during the current study are available from the corresponding author on reasonable request.

\section{Consent for Publication Not applicable.}

Code Availability Not applicable.

Author contributions All authors contributed to the study's conception and design. Material preparation, data collection, and analysis were performed by AP and AK. The first draft of the manuscript was written by AP and all authors commented on previous versions of the manuscript. All authors read and approved the final manuscript.

Open Access This article is licensed under a Creative Commons Attribution-NonCommercial 4.0 International License, which permits any non-commercial use, sharing, adaptation, distribution and reproduction in any medium or format, as long as you give appropriate credit to the original author(s) and the source, provide a link to the Creative Commons licence, and indicate if changes were made. The images or other third party material in this article are included in the article's Creative Commons licence, unless indicated otherwise in a credit line to the material. If material is not included in the article's Creative Commons licence and your intended use is not permitted by statutory regulation or exceeds the permitted use, you will need to obtain permission directly from the copyright holder. To view a copy of this licence, visit http://creativecommons.org/licenses/by-nc/4.0/.

\section{References}

1. Lim LM, McStea M, Chung WW, Nor Azmi N, Abdul Aziz SA, Alwi S, et al. Prevalence, risk factors and health outcomes associated with polypharmacy among urban communitydwelling older adults in multi-ethnic Malaysia. PLoS ONE. 2017;12(3):e0173466. https://doi.org/10.1371/journal.pone.01734 66.

2. Shruthi R, Jyothi R, Pundarikaksha HP, Nagesh GN, Tushar TJ. A study of medication compliance in geriatric patients with chronic illnesses at a tertiary care hospital. J Clin Diagn Res.
2016;10(12):Fc40-3. https://doi.org/10.7860/jcdr/2016/21908 .9088 .

3. Wooten JM. Pharmacotherapy considerations in elderly adults. Sout Med J. 2012;105(8):437-45. https://doi.org/10.1097/ SMJ.0b013e31825fed 90.

4. Lavan AH, Gallagher P. Predicting risk of adverse drug reactions in older adults. Ther Adv Drug Saf. 2016;7(1):11-22. https://doi. org/10.1177/2042098615615472.

5. Alhawassi TM, Krass I, Bajorek BV, Pont LG. A systematic review of the prevalence and risk factors for adverse drug reactions in the elderly in the acute care setting. Clin Interv Aging. 2014;9:2079-86. https://doi.org/10.2147/cia.S71178.

6. Chan DC, Chen JH, Kuo HK, We CJ, Lu IS, Chiu LS, et al. Drugrelated problems (DRPs) identified from geriatric medication safety review clinics. Arch Gerontol Geriart. 2012;54(1):168-74. https://doi.org/10.1016/j.archger.2011.02.005.

7. Hailu BY, Berhe DF, Gudina EK, Gidey K, Getachew M. Drug related problems in admitted geriatric patients: the impact of clinical pharmacist interventions. BMC Geriatr. 2020;20(1):13. https ://doi.org/10.1186/s12877-020-1413-7.

8. Ahmad A, Mast MR, Nijpels G, Elders PJ, Dekker JM, Hugtenburg JG. Identification of drug-related problems of elderly patients discharged from hospital. Patient Prefer Adher. 2014;8:155-65. https://doi.org/10.2147/ppa.S48357.

9. Watanabe JH, McInnis T, Hirsch JD. Cost of prescription drugrelated morbidity and mortality. Annals Pharm. 2018;52(9):82937. https://doi.org/10.1177/1060028018765159.

10. Cipolle RJ, Strand LM, Morley PC. Pharmaceutical care practice: the patient-centered approach to medication management. New York, NY: McGraw Hill Professional; 2012.

11. Basger BJ, Moles RJ, Chen TF. Application of drug-related problem (DRP) classification systems: a review of the literature. Eur J Clin Pharmacol. 2014;70(7):799-815. https://doi.org/10.1007/ s00228-014-1686-x.

12. Ferreira JM, Galato D, Melo AC. Medication regimen complexity in adults and the elderly in a primary healthcare setting: determination of high and low complexities. Pharm Pract (Granada). 2015;13(4):659. https://doi.org/10.18549/PharmPract .2015.04.659.

13. O'Connell MB, Chang F, Tocco A, Mills ME, Hwang JM, Garwood CL, et al. Drug-related-problem outcomes and program satisfaction from a comprehensive brown bag medication review. J Am Geriatr Soc. 2015;63(9):1900-5. https://doi.org/10.1111/ jgs. 13597.

14. Garcia-Caballos M, Ramos-Diaz F, Jimenez-Moleon JJ, BuenoCavanillas A. Drug-related problems in older people after hospital discharge and interventions to reduce them. Age Ageing. 2010;39(4):430-8. https://doi.org/10.1093/ageing/afq045.

15. Semcharoen K, Supornpun S, Nathisuwan S, Kongwatcharapong J. Characteristic of drug-related problems and pharmacists' interventions in a stroke unit in Thailand. Int J Clin Pharm. 2019;41(4):880-7. https://doi.org/10.1007/s11096-019-00832-4.

16. Kongkaew C, Methaneethorn J, Mongkhon P, Dechanont S, Taburee W. Drug-related problems identified at patients' home: a prospective observational study in a rural area of Thailand. J Patient Saf. 2017. https://doi.org/10.1097/pts.0000000000000404.

17. Dechanont S, Jedsadayanmata A, Butthum B, Kongkaew C. Hospital outpatient visits associated with medication-related problems in Thailand: a multicenter prospective observational study. J Patient Saf. 2017. https://doi.org/10.1097/pts.000000000000036 7

18. von Elm E, Altman DG, Egger M, Pocock SJ, Gøtzsche PC, Vandenbroucke JP. The Strengthening the Reporting of Observational Studies in Epidemiology (STROBE) statement: guidelines for reporting observational studies. PLoS Med. 2007;4(10):e296. https://doi.org/10.1371/journal.pmed.0040296. 
19. Bryant J, Prohmmo A. Payment mechanisms and prescriptions in four Thai hospitals. Health Policy. 2005;73(2):160-71. https://doi. org/10.1016/j.healthpol.2004.11.011.

20. World Health Organization. The Asia-Pacific perspective: redefining obesity and its treatment. Geneva: World Health Organization; 2000.

21. Sritara P, Cheepudomwit S, Chapman N, Woodward M, Kositchaiwat $\mathrm{C}$, Tunlayadechanont $\mathrm{S}$, et al. Twelve-year changes in vascular risk factors and their associations with mortality in a cohort of 3499 Thais: the Electricity Generating Authority of Thailand Study. Int J Epidemiol. 2003;32(3):461-8. https://doi.org/10.1093/ ije/dyg 105.

22. Chen LK, Liu LK, Woo J, Assantachai P, Auyeung TW, Bahyah KS, et al. Sarcopenia in Asia: consensus report of the Asian Working Group for Sarcopenia. J Am Med Dir Assoc. 2014;15(2):95101. https://doi.org/10.1016/j.jamda.2013.11.025.

23. Cohen JT, Manor Y. Swallowing disturbance questionnaire for detecting dysphagia. Laryngoscope. 2011;121(7):1383-7. https ://doi.org/10.1002/lary.21839.

24. Naranjo CA, Busto U, Sellers EM, Sandor P, Ruiz I, Roberts EA, et al. A method for estimating the probability of adverse drug reactions. Clin Pharmacol Ther. 1981;30(2):239-45. https://doi. org/10.1038/clpt.1981.154.

25. Cramer JA, Mattson RH, Prevey ML, Scheyer RD, Ouellette VL. How often is medication taken as prescribed? A novel assessment technique. JAMA. 1989;261(22):3273-7.

26. Masnoon N, Shakib S, Kalisch-Ellett L, Caughey GE. What is polypharmacy? A systematic review of definitions. BMC Geriatr. 2017;17(1):230. https://doi.org/10.1186/s12877-017-0621-2.

27. O'Mahony D, O'Sullivan D, Byrne S, O'Connor MN, Ryan C, Gallagher P. STOPP/START criteria for potentially inappropriate prescribing in older people: version 2. Age Ageing. 2015;44(2):213-8. https://doi.org/10.1093/ageing/afu145.
28. American Geriatrics Society. 2019 Updated AGS Beers Criteria ${ }^{\circledR}$ for potentially inappropriate medication use in older adults. J Am Geriatr Soc. 2019;67(4):674-94. https://doi.org/10.1111/ jgs.15767.

29. Motter FR, Fritzen JS, Hilmer SN, Paniz EV, Paniz VMV. Potentially inappropriate medication in the elderly: a systematic review of validated explicit criteria. Eur J Clin Pharmacol. 2018;74(6):679-700. https://doi.org/10.1007/s00228-018-2446-0.

30. Wang X, Yang J, Yu X, Wang Z, Wang H, Liu L. Characterization of drug-related problems and associated factors in ambulatory patients in China. J Clin Pharm Ther. 2020;45:1058-65. https:// doi.org/10.1111/jcpt.13161.

31. Walsh CA, Cahir C, Tecklenborg S, Byrne C, Culbertson MA, Bennett KE. The association between medication nonadherence and adverse health outcomes in ageing populations: a systematic review and meta-analysis. Br J Clin Pharmacol. 2019;85(11):2464-78. https://doi.org/10.1111/bcp.14075.

32. Zelko E, Klemenc-Ketis Z, Tusek-Bunc K. Medication adherence in elderly with polypharmacy living at home: a systematic review of existing studies. Mater Sociomed. 2016;28(2):129-32. https:// doi.org/10.5455/msm.2016.28.129-132.

33. Yap AF, Thirumoorthy T, Kwan YH. Systematic review of the barriers affecting medication adherence in older adults. Geriatr Gerontol Int. 2016;16(10):1093-101. https://doi.org/10.1111/ ggi.12616.

34. Ahmed B, Nanji K, Mujeeb R, Patel MJ. Effects of polypharmacy on adverse drug reactions among geriatric outpatients at a tertiary care hospital in Karachi: a prospective cohort study. PLoS ONE. 2014;9(11):e112133. https://doi.org/10.1371/journal.pone.01121 33.

35. Fillit HM, Rockwood K, Young JB. Brocklehurst's textbook of geriatric medicine and gerontology e-book. Philadelphia, PA: Elsevier Health Sciences; 2016. 